Gazi University
Journal of Science
http://dergipark.gov.tr/gujs

\title{
Early Estimation of Sewerage Line Costs with Regression Analysis
}

\author{
Murat SUERI ${ }^{1, *}$ (D), Mursel ERDAL ${ }^{2}$ \\ ${ }^{1}$ İlbank Inc., Head Office, Investment Coordination Department, 06530, Ankara, Turkey \\ ${ }^{2}$ Gazi University, Faculty of Technology, Department of Civil Engineering, 06500, Ankara, Turkey
}

\author{
Highlights \\ - This paper focuses on early estimation of sewerage line costs. \\ - Regression Analysis method is proposed for early cost estimation in the study. \\ - Very successful estimations were obtained.
}

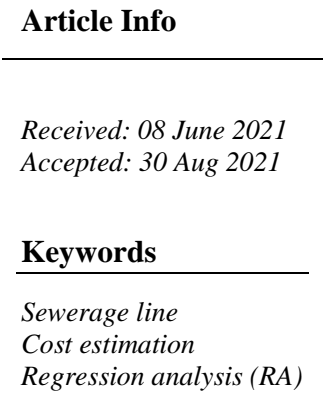

\section{INTRODUCTION}

The purpose of cost estimation is to identify the cost of the required service or product by using limited resources effectively. Completing the task with maximum productivity is only possible when the cost of the relevant task is estimated correctly and managed effectively within the acceptable cost limitations. With well-prepared cost estimation, necessities such as materials for application, equipment and other resources can be specified. In order to make effective planning and actual budget preparation, all projects require cost estimation $[1,2]$.

In the construction industry, it is quite important to create the financial model correctly during the idea phase of the project, in order to prevent cash flow problems and national wealth losses. This is only possible by estimating the cost correctly in predesign period [3-6].

In the last century, Turkey has experienced intense population growth and unplanned urbanization, and urban areas with insufficient physical infrastructure have been formed [7]. Sewer lines are of great importance among infrastructure facilities.

There are several studies related to cost estimation aiming to increase the efficiency of public resources, but none of them focused on sewer lines. Within the scope of this study, matters to be taken into account while making cost estimation of sewer lines are examined in detail by using the regression analysis (RA) method.

In the past years, works related to the sewer lines tendered by İlbank, municipalities, and water and sewerage administrations were examined. They have determined that an annual average of 450 sewer line 
tenders are being made and the total line length of these works is around $11000000 \mathrm{~m}$. It is very important for both the investor and the contractor to know the costs of the sewerage networks, which have an average business volume of $11000000 \mathrm{~m}$ per year. In this context, the aim of the study is to determine the factors that affect the sewerage line cost, to examine the effect weights of these factors, and to create successful cost outputs that can increase the efficiency of the use of public resources with the RA method of these weights and data inputs.

\section{LITERATURE REVIEW}

By using back-propagating Artificial Neural Network (ANN) model, Elazouni, Nosair, Mohieldin and Mohamed [8] have tried to estimate required structure resources for different silo constructions which are in design phases. The results of this study are compared to RA results. Considering structure estimation problems, the ANN method has shown more efficient and successful results compared to traditional methods.

Kim, An and Kang [9] have compared RA, ANN and Case-Based Reasoning methods' estimation performances by using 530 residence type structures' cost data which have been built between 1997-2000 in Korea. The best result among these three methods is given by the ANN method using the backpropagation algorithm. In this study, the following disadvantage for the ANN method is shown that when new events are added to the study database, ANN is needed to be educated again, hence this method will consume more time compared to the other methods.

Sodikov [10] has studied cost estimation of infrastructure projects in the two developing countries, Poland and Thailand. In this study, Sodikov pointed out that the correct calculation of cost analysis of highway projects is an important problem for project evaluation, planning, and feasibility, not only for developed countries; but also especially for developing countries. As a result of this study, in comparison to the ANN method, the margin of error of the RA method is $12 \%$ in Poland and $4 \%$ in Thailand. It is also concluded that when project-related data is limited and it is hard to find a correlation between variables, the ANN method is more advantageous.

Baykan [11] has used 62 residence data during the learning phase to create a system for resource estimation and has realized his aim ultimately with necessary resource estimation for the projects at the design phase. In the meantime, comparing his estimations made by using multiple RA method and ANN method, Baykan found out that The ANN method can make successful estimations. Besides, Baykan has evaluated two methods, considering the time needed for the completion of the analysis, for situations when there are more than one output estimations and by pointing out that, with multiple linear RA each output parameter should be correlated separately with input block, it takes a lot less time to complete the estimation when compared to ANN method.

Öztürk [12] has developed pre-cost estimation model for rail systems and subway projects, by using multiple variable RA and ANN methods. Both approaches have been applied to the 16 completed projects' data sets, which were available during the pre-designing phase and according to the results of each method, the ANN test sample's error ratio $(5,76)$ is somewhat higher than the RA test sample's error ratio $(2,32)$. As a result of this study, two successful cost estimation models have been developed.

Bahadır [13] has used 100 project data, 80 of which have been used of educational data and the rest have been used as test data. In this study, an offer price which is estimated by using the ANN method is also tried to be specified by using the RA method and MAPE value is found as $38,87 \%$. When ANN and RA methods have been compared, it has been realized that the ANN method can give more successful results for the offer creation process where exists uncertainties.

Kasapl1 [14] has used 73 of İlbank Inc. approved domestic water project data between 2013-2017. As a result of the study, in an environment where there is no investment cost estimation automation, it was seen that the estimation results obtained from ANN models created to estimate the construction cost of drinking 
water network with the determined independent input variables, gave more consistent and applicable results than the RA estimation results.

Rui and friends [15] aimed to provide a reference for pipeline construction by analyzing historical pipelines' cost data. In this study, 412 pipeline cost data were used published in Petroleum and Gas Magazine between years 1992 and 2008. These 412 pipelines have been evaluated by assessing distribution and share of cost component, pipeline diameter, pipeline length, pipeline capacity, year of completion and pipeline locations. In conclusion, it has been shown that learning rate and construction cost may change depending on pipeline diameter, pipeline length, pipeline locations and other criteria. This study also analyzed the causes of pipeline construction cost differences between different groups.

Rui and friends [16] have researched pipeline projects' excess costs in their study. Within the years 1992 and 2008, a total of 412 pipeline projects' material cost, labor cost, miscellaneous cost, right of way cost, total cost, pipeline diameter, pipeline length, pipeline location, and year of completion data has been collected. Statistical methods were used in order to specify cost overflow distribution and causes of excessive spending. Analysis results have shown that pipeline length, capacity, diameter, location, and year of completion may affect construction cost overflow differently.

The evolution of investment projects is usually complex and volatile since they include expectations about the future and long-term preparation. Clements and Si [17] have investigated an important aspect of this volatility by examining the nature of investment starting from the bright idea at the beginning and until the finalization and operational phase of the project. By using a rich database of Australian resource development projects and with the help of the index number approach, pipeline and preparation time were used to measure the project cost increase. The key factor of the success probability of the projects is specified with a binary selection model. Finally, they used a Markov chain approach to model the transitions of projects at one stage in the pipeline and to examine the effects of regulatory reform that has the effect of accelerating the flow of projects.

Kaiser and Liu [18] have described pipeline construction cost factors and gas transmission construction and compressor-station cost statistics and regression models have been evaluated. From 2014-2019, 2063 miles of gas transmission pipeline and 1,9 million horsepower compression regulated by the Federal Energy Regulatory Commission were installed in the USA at a unit cost of $\$ 5,72$ million per mile and $\$ 3030$ per horsepower. Line length and pipe diameter were the only variables needed to develop robust linear models of pipeline construction cost.

Kaiser $[19,20]$ has evaluated publicly available data sources for onshore and offshore pipeline installation and decommissioning activities in the USA. Related activities and processes, cost influencing factors, cost statistics and analysis limitations have been presented for onshore and offshore pipeline installation and decommissioning. In the first part of the two-part review, an overview of pipeline fabrication and API 5L specifications have introduced the relevant terminology and key pipeline requirements, and a description of cost estimation procedures, normalization, and data sources provides the evaluation framework. The second part of this two-part review has described the cost along with the hypothetical pipeline decommissioning cost algorithms for the deep waters of the Gulf of Mexico. Over long periods, significant temporal effects have entered cost statistics due to inflation, market conditions, changes in legislation and technology, and spatial effects are always present due to differences in geological conditions, infrastructure, and terrain. Most factors have been unobservable and unsuitable for evaluation, but there have been many similarities in processes and infrastructure that allow normalized cost to serve as a useful first-order benchmark.

\section{REGRESSION ANALYSIS METHOD}

RA was first put forward by Sir Francis Galton in the 1950s [21]. RA is defined as illustrating the relationships between one dependent variable and one or more independent variables with a mathematical equation [22-24]. 
The aim of RA is to find the most suitable equation to specify and represent the relationship between dependent and independent variables. The mathematical function which is configured to show the relationship between the variables not only indicates the functional way for the relationship but also presents the possibility to make predictions [25].

RA can be used for specifying the correlation between two or more variables with cause and effect relationships and making predictions by using this relationship. In nature, one can encounter cause and effect relationships in many events.

RA is used for measuring the correlation between two or more quantitative variables. If one variable is used, the method is called single variable RA, and if more than one variable is used, the method is called multiple variable RA. By using RA, the correlation between the variables, and the strength of this correlation (if present) can be known.

\section{PREPARATION OF DATA SET}

Data belonging to 182 sewerage line projects were used in the development of the models. These projects were used in public tenders between 2014-2020. All of the approximate cost studies of these projects were done by the same technical team. In this way, the studies are consistent with each other and in the same format. Pipe diameter $(\mathrm{mm})$, line length $(\mathrm{m})$, excavation depth $(\mathrm{m})$, manhole amount (pcs), excavation amount $\left(\mathrm{m}^{3}\right)$, filling amount $\left(\mathrm{m}^{3}\right)$, filling type, shoring type, excavation class and real cost $(\$)$ parameters have been determined from these studies.

Verbal variables are not used in RA solutions. In order to see the effect of verbal variables on cost, the verbal parameter of the excavation class was transformed into a numerical parameter. For this transformation, unit prices of soil, resentment, soft rock, hard rock and very hard rock excavations were used. The cost of $1 \mathrm{~m}^{3}$ excavation for each project was divided by the unit price for the soil excavation with the lowest unit price, and the excavation class coefficient (ECC) was determined and defined with the equation, given in Equation (1)

$$
E C C=C_{S}+1,83 * C_{R}+3,06 * C_{S R}+6,26 * C_{H R}+8,41 * C_{V H R} .
$$

In the equation;
ECC : Excavation Class Coefficient
$\mathrm{C}_{S} \quad:$ Percentage of Soil in Excavation
$\mathrm{C}_{\mathrm{R}} \quad:$ Percentage of Resentment in the Excavation
$\mathrm{C}_{\mathrm{SR}} \quad$ : Percentage of Soft Rock in the Excavation
$\mathrm{C}_{\mathrm{HR}} \quad:$ Percentage of Hard Rock in the Excavation
$\mathrm{C}_{\mathrm{VHR}} \quad$ : Percentage of Very Hard Rock in the Excavation represents.

Inserting the data of 2 randomly chosen (Equations (2)-(3)) excavation classes from the project, into Equation (1), the excavation class coefficient is calculated as indicated below. The parameters and results used in the calculation are given in Table 1.

$$
\begin{aligned}
& E C C=0,96+1,83 * 0,04+3,06 * 0+6,26 * 0+8,41 * 0=1,03 \\
& E C C=0,05+1,83 * 0,70+3,06 * 0,25+6,26 * 0+8,41 * 0=2,10
\end{aligned}
$$


Table 1. Excavation class values used in sample calculation

\begin{tabular}{|l|l|l|l|}
\hline Variable & Parameter & Example 1 & Example 2 \\
\hline Percentage of Soil in Excavation & $\mathrm{C}_{\mathrm{S}}$ & $96 \%$ & $5 \%$ \\
\hline Percentage of Resentment in the Excavation & $\mathrm{C}_{\mathrm{R}}$ & $4 \%$ & $70 \%$ \\
\hline Percentage of Soft Rock in the Excavation & $\mathrm{C}_{\mathrm{SR}}$ & - & $25 \%$ \\
\hline Percentage of Hard Rock in the Excavation & $\mathrm{C}_{\mathrm{HR}}$ & - & - \\
\hline Percentage of Very Hard Rock in the Excavation & $\mathrm{C}_{\mathrm{VHR}}$ & - & - \\
\hline Excavation Class Coefficient & ECC & 1,03 & 2,10 \\
\hline
\end{tabular}

SPSS Statistics 25 software has been used to establish the correlations between determined parameters and shown in Table 2.

Table 2. Correlation between variables

\begin{tabular}{|c|c|c|c|c|c|c|c|c|}
\hline & 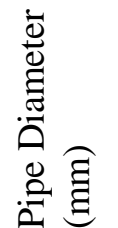 & 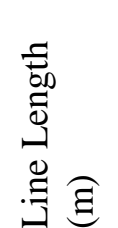 & 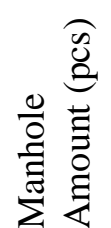 & 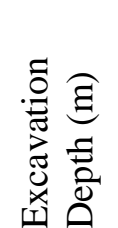 & 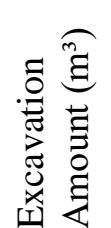 & 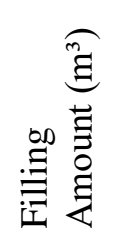 & 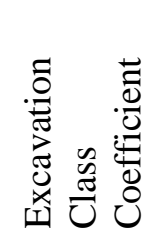 & 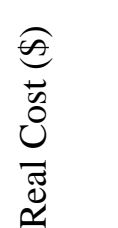 \\
\hline $\begin{array}{l}\text { Pipe Diameter } \\
(\mathrm{mm})\end{array}$ & 1,000 & $-0,311$ & $-0,307$ & 0,340 & $-0,244$ & $-0,241$ & 0,108 & $-0,222$ \\
\hline Line Length (m) & $-0,311$ & 1,000 & 0,991 & $-0,263$ & 0,951 & 0,918 & 0,018 & 0,948 \\
\hline $\begin{array}{l}\text { Manhole Amount } \\
\text { (pcs) }\end{array}$ & $-0,307$ & 0,991 & 1,000 & $-0,261$ & 0,950 & 0,921 & 0,021 & 0,932 \\
\hline $\begin{array}{l}\text { Excavation Depth } \\
(\mathrm{m})\end{array}$ & 0,340 & $-0,263$ & $-0,261$ & 1,000 & $-0,203$ & $-0,187$ & $-0,215$ & $-0,164$ \\
\hline $\begin{array}{l}\text { Excavation } \\
\text { Amount }\left(\mathrm{m}^{3}\right)\end{array}$ & $-0,244$ & 0,951 & 0,950 & $-0,203$ & 1,000 & 0,986 & 0,028 & 0,910 \\
\hline $\begin{array}{l}\text { Filling Amount } \\
\left(\mathrm{m}^{3}\right)\end{array}$ & $-0,241$ & 0,918 & 0,921 & $-0,187$ & 0,986 & 1,000 & 0,004 & 0,876 \\
\hline $\begin{array}{l}\text { Excavation Class } \\
\text { Coefficient }\end{array}$ & 0,108 & 0,018 & 0,021 & $-0,215$ & 0,028 & 0,004 & 1,000 & 0,043 \\
\hline Real Cost (\$) & $-0,222$ & 0,948 & 0,932 & $-0,164$ & 0,910 & 0,876 & 0,043 & 1,000 \\
\hline
\end{tabular}

Once, the correlation results given in Table 2 were examined, the necessary data; excavation class coefficient in Equation (1), easily identifiable data of the sewer line project such as pipe diameter (mm), line length $(\mathrm{m})$, excavation depth $(\mathrm{m})$ and the real cost $(\$)$ data were selected to be used in the analysis. While selecting the parameters, the following was taken into account that the variables have a high correlation with the real cost and the variables have a very high correlation with the other variables. An example of the data set used in RA is given in Table 3.

Table 3. Database format used in RA

\begin{tabular}{|l|l|l|l|l|l|}
\hline \multirow{2}{*}{$\begin{array}{l}\text { Variable } \\
\text { Number }\end{array}$} & Real Cost $(\$)$ & $\begin{array}{l}\text { Pipe Diameter } \\
(\mathrm{mm})\end{array}$ & $\begin{array}{l}\text { Line Length } \\
(\mathrm{m})\end{array}$ & $\begin{array}{l}\text { Excavation } \\
\text { Depth }(\mathrm{m})\end{array}$ & $\begin{array}{l}\text { Excavation } \\
\text { Class } \\
\text { Coefficient }\end{array}$ \\
\cline { 2 - 6 } & $\mathrm{RC}$ & $\mathrm{D}$ & $\mathrm{L}$ & $\mathrm{H}$ & ECC \\
\hline 1 & 1186936,19 & 200 & 13306 & 2,21 & 1,03 \\
\hline
\end{tabular}




\section{ANALYSIS APPLICATIONS}

In order to make an early estimation of sewage line costs, regression analyzes were made by using the values of 182 different sewer pipelines of 5 variables in the data set given in Table 3 . Regression equations and $\mathrm{R}^{2}$ coefficients obtained as a result of RA are given in Table 4.

Table 4. Regression equations and $R^{2}$ values

\begin{tabular}{|c|c|c|c|}
\hline $\begin{array}{l}\text { Row } \\
\text { Number }\end{array}$ & Equation & Explanation & $\mathbf{R}^{2}$ \\
\hline \multicolumn{4}{|c|}{ Equations of One Variable } \\
\hline 1 & $E C=926032,656-958,259 \times D$ & $\mathrm{D}[\mathrm{mm}]$ & 0,049 \\
\hline 2 & $E C=919932,394-118080,917 \times H$ & $\mathrm{H}[\mathrm{m}]$ & 0,027 \\
\hline 3 & $E C=112327,811+75,060 \times L$ & $\mathrm{~L}[\mathrm{~m}]$ & 0,899 \\
\hline 4 & $E C=390974,829+90684,014 \times E C C$ & ECC & 0,002 \\
\hline \multicolumn{4}{|c|}{ Equations of Two Variables } \\
\hline 5 & $E C=1091256,032-811,389 \times D-72071,573 \times H$ & $\mathrm{D}[\mathrm{mm}], \mathrm{H}[\mathrm{m}]$ & 0,058 \\
\hline 6 & $E C=-35781,660+353,119 \times D+77,072 \times L$ & $\mathrm{D}[\mathrm{mm}], \mathrm{L}[\mathrm{m}]$ & 0,905 \\
\hline 7 & $E C=677001,918-989,595 \times D+143.125,377 \times E C C$ & $\mathrm{D}[\mathrm{mm}], \mathrm{ECC}$ & 0,054 \\
\hline 8 & $E C=-104831,137+76,992 \times L+66827,221 \times H$ & $\mathrm{~L}[\mathrm{~m}], \mathrm{H}[\mathrm{m}]$ & 0,907 \\
\hline 9 & $E C=13461,877+75,024 \times L+54309,229 \times E C C$ & $\mathrm{~L}[\mathrm{~m}], \mathrm{ECC}$ & 0,900 \\
\hline 10 & $E C=885618,168-116862,527 \times H+16752,613 \times E C C$ & $\mathrm{H}[\mathrm{m}], \mathrm{ECC}$ & 0,027 \\
\hline \multicolumn{4}{|c|}{ Equations of Three Variables } \\
\hline 11 & $E C=-174619,382+259,228 \times D+78,123 \times L+54843,940 \times H$ & $\mathrm{D}[\mathrm{mm}], \mathrm{L}[\mathrm{m}], \mathrm{H}[\mathrm{m}]$ & 0,910 \\
\hline 12 & $E C=-95947,065+344,161 \times D+76,998 \times L+35113,948 \times E C C$ & $\mathrm{D}[\mathrm{mm}], \mathrm{L}[\mathrm{m}], \mathrm{ECC}$ & 0,905 \\
\hline 13 & $\begin{array}{l}E C=902938,168-62825,182 \times H+96049,185 \times E C C- \\
851,260 \times D\end{array}$ & $\mathrm{H}[\mathrm{m}], \mathrm{D}[\mathrm{mm}], \mathrm{ECC}$ & 0,060 \\
\hline 14 & $\begin{array}{l}E C=-312560,143+77,146 \times L+74501,013 \times H+ \\
100411,974 \times E C C\end{array}$ & $\mathrm{~L}[\mathrm{~m}], \mathrm{H}[\mathrm{m}], \mathrm{ECC}$ & 0,909 \\
\hline \multicolumn{4}{|c|}{ Equation of Four Variables } \\
\hline 15 & $\begin{array}{l}E C=-331951,832+225,517 \times D+78,100 \times L+80438,203 \times E C C \\
+62549,617 \times H\end{array}$ & $\begin{array}{l}\mathrm{D}[\mathrm{mm}], \mathrm{L}[\mathrm{m}], \mathrm{H}[\mathrm{m}] \\
\mathrm{ECC}\end{array}$ & 0,911 \\
\hline
\end{tabular}

For univariate linear RA, the line length parameter with $\mathrm{R}^{2}=0,899$ gave the best result (Figure 1(a)). Comparison of the estimated cost, calculated by the equation, determined by using the line length parameter and the real cost is given in Figure 1(b).

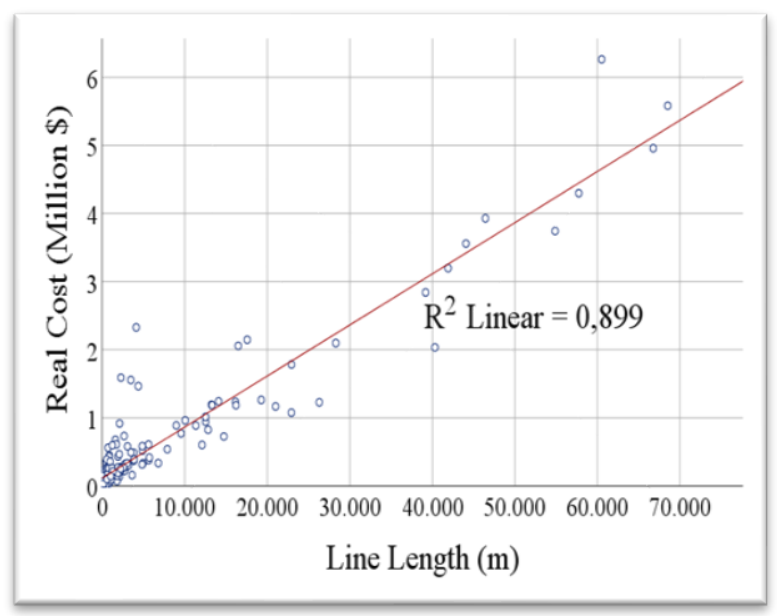

(a)

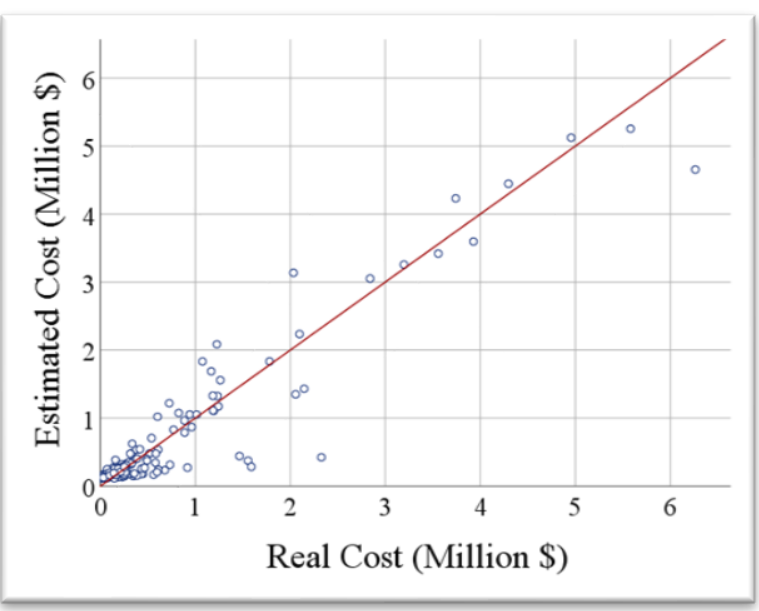

(b)

Figure 1. (a) Real cost regression graph with line length,

(b) Comparison of estimated cost values and real cost values 
In bivariate linear regressions, the RA between the line length and excavation depth variables with $\mathrm{R}^{2}=$ 0,907 and the real cost yielded the most successful result (Figure 2(a)). In Figure 2(b), sewage line cost estimated with the help of the determined regression equation was compared with the real cost.

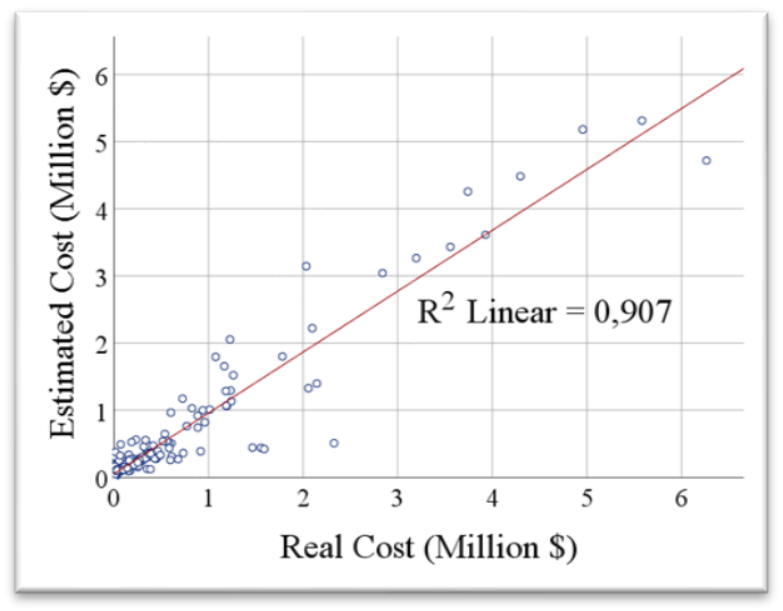

(a)

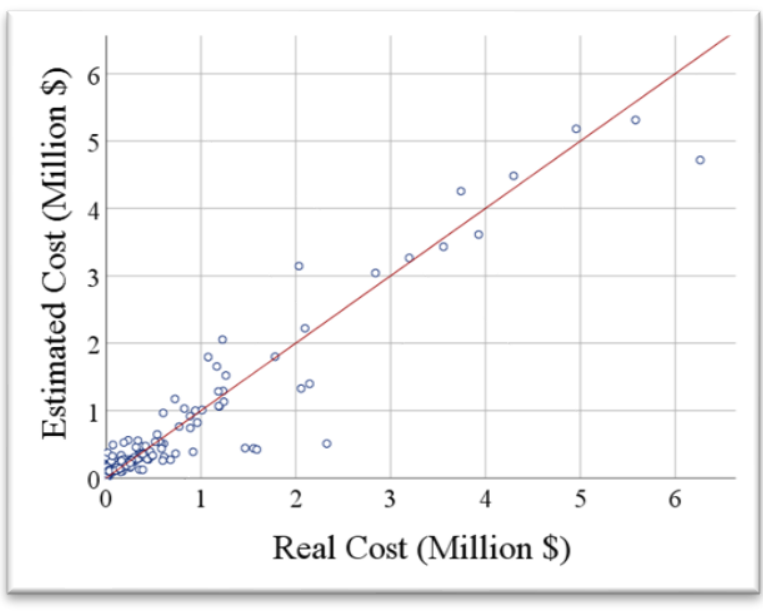

(b)

Figure 2. (a) Real cost regression graph with line length and excavation depth,

(b) Comparison of estimated cost values and real cost values

In three-variable linear regressions, the RA performed between the variables of pipe diameter, line length and excavation depth with $\mathrm{R}^{2}=0,910$ and the real cost yielded the most successful result (Figure 3(a)). Sewage line cost estimated with the help of the determined regression equation was compared with the real cost, as shown in Figure 3(b).

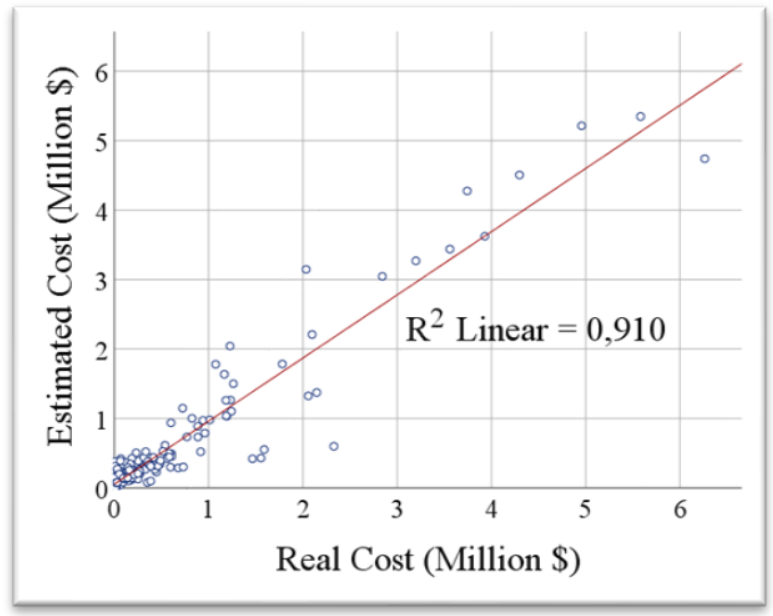

(a)

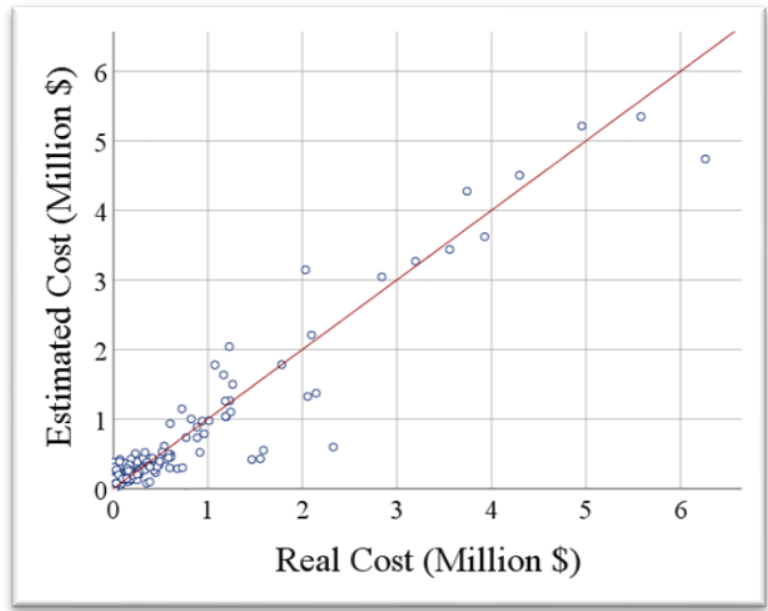

(b)

Figure 3. (a) Real cost regression graph with pipe diameter, line length and excavation depth,

(b) Comparison of estimated cost values and real cost values

In the linear regression where all variables (pipe diameter, excavation class coefficient, line length and excavation depth) are included, a correlation coefficient of $\mathrm{R}^{2}=0,911$ was reached. This value has the coefficient with the largest relationship among all RA (Figure 4(a)). Sewerage line cost estimated with the help of the determined regression equation was compared with the real cost as shown below in Figure 4(b). 


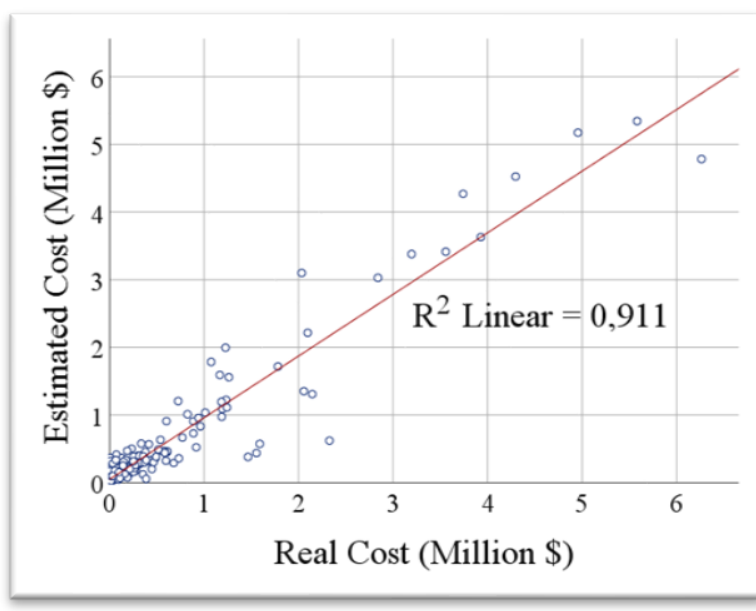

(a)

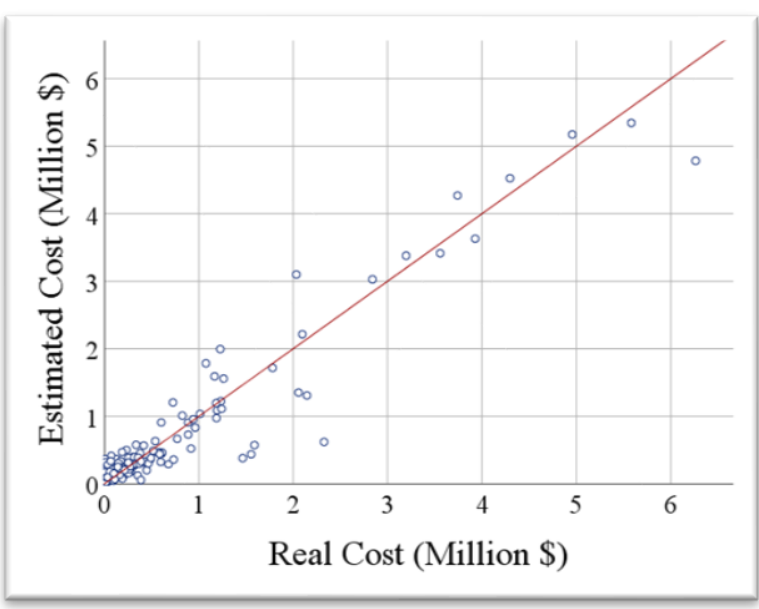

(b)

Figure 4. (a) Real cost regression graph with pipe diameter, excavation class coefficient, line length and excavation depth,

(b) Comparison of estimated cost values and real cost values

\section{THE RESEARCH FINDINGS AND DISCUSSION}

The cost estimation was made by using the equation with the highest $\mathrm{R}^{2}=0,911$ coefficient and data of 2 randomly selected sewer line projects (Equations (4)-(5)). Parameters used for the estimation and results obtained from the calculation are given in Table 5.

$$
\begin{gathered}
E C=-331951,832+225,517 * 200+78,100 \times 13306+80438,203 \times 1,03 \\
+62549,617 \times 2,21=973436,17 \\
E C=-331951,832+225,517 * 200+78,100 \times 57739+80438,203 \times 2,10 \\
+62549,617 \times 2,14=4525343,87
\end{gathered}
$$

Table 5. Parameters and values used in sample calculation

\begin{tabular}{|l|l|l|l|}
\hline Variable & Parameter & Example 1 & Example 2 \\
\hline Real Cost (\$) & RC & 1186936,19 & 4296604,12 \\
\hline Pipe Diameter (mm) & D & 200 & 200 \\
\hline Line Length (m) & L & 13306 & 57739 \\
\hline Excavation Depth (m) & H & 2,21 & 2,14 \\
\hline Excavation Class Coefficient & ECC & 1,03 & 2,10 \\
\hline Estimated Cost (\$) & EC & 973436,17 & 4525343,87 \\
\hline
\end{tabular}

As can be seen from Table 5, the estimated cost value for Example 1 is $\$ 973436.17$, while the real cost value is $\$ 1186936.19$. As a result, the cost estimation was made with an accuracy of $82,01 \%$ with the proposed regression equation. Similarly, while the estimated cost value for Example 2 is $\$ 4525343,87$, the real cost value is $\$ 4296604,12$. Here, the cost estimation was made with $94,68 \%$ accuracy. 


\section{RESULTS}

In this study, RA was made for early estimation of sewage pipeline costs. Data belonging to 182 sewer line projects were used for this purpose. Data on pipe diameter, line length, excavation depth, manhole amount, excavation amount, filling amount, filling type, shoring type, excavation class and actual cost parameters were determined through the projects. Correlations were made between variables and their weights were examined. As a result, excavation class coefficient, easily identifiable data of the sewer line project such as pipe diameter $(\mathrm{mm})$, line length $(\mathrm{m})$, excavation depth $(\mathrm{m})$ and the real cost $(\$)$ data were selected to be used in the analysis.

As a result of univariate $R A$, the analysis with the highest level of correlation with $R^{2}=0,899$ was realized between the length of the sewer pipeline and the real cost. The analysis with the highest level of correlation among the bivariate RA was between the length of the sewer pipeline and the depth of the excavation and the real cost with the coefficient of $\mathrm{R}^{2}=0,907$. The analysis which has the highest level of relationship with the coefficient $\mathrm{R}^{2}=0,910$ among the three variable RA was found as a result of the RA performed between the length of the sewer pipeline, the depth of the excavation and the pipe diameter and the real cost. The equation with the highest degree of relationship is the RA equation with $\mathrm{R}^{2}=0,911$ in which all variables are used.

In conclusion, it has been realized that results obtained with RA methods for the early estimation of sewage pipeline costs are very close to the real costs. In this context, it is concluded that the proposed method can be used safely, especially when cost estimation is needed at the beginning or at the design stage.

This study was carried out using the data of Turkish sewerage lines. In future research, data from other countries can be collected and compared. In addition, future studies should ensure that the $\mathrm{R}^{2}$ value is improved.

\section{CONFLICTS OF INTEREST}

No conflict of interest was declared by the authors.

\section{REFERENCES}

[1] Topçu, G., "Cost-related operations in the building production process: estimation, planning, control”, MS Thesis, İstanbul Technical University, İstanbul, 25-32, (1989).

[2] Uğur, L.O., Kanıt, R., Erdal, H., Namlı, E., Erdal, H.İ., Baykan, U.N., Erdal, M., "Enhanced predictive models for construction costs: A case study of Turkish mass housing sector", Computational Economics, 53(4): 3336-3344, (2019).

[3] Polat, A.P., Çıracı, M., "A database model for pre-design-phase building cost estimate in Turkey", İTÜ Journal/a, 4(2): 59-69, (2005).

[4] Özmaden, M.Ş., Erdal, M., "Performance analysis of methods used in the cost estimation of residential buildings", Konya Journal of Engineering Sciences, 8(4): 970-985, (2020).

[5] Kanıt, R., Baykan, U.N., Erdal, M., "Investigation of the effects of constrained source conditions on the structure cost", Journal of Polytechnic, 8(2): 209-221, (2005).

[6] Özyürek, İ., Erdal, M., "Assessment of qualification criteria described in Public Procurement Law Code 4734 in construction works by analytic hierarchy process (AHP)", Gazi University Journal of Science, 31(2): 437-454, (2018). 
[7] Yıldız, S., Kıvrak, S., Gültekin, A.B., Arslan, G., "Built environment design - social sustainability relation in urban renewal", Sustainable Cities and Society, 60: 102173, (2020).

[8] Elazouni, A.M., Nosair, I.A., Mohieldin, Y.A., Mohamed, A.G., "Estimating resource requirements at conceptual design stage using neural networks", Journal of Computing in Civil Engineering, 11: 217-223, (1997).

[9] Kim, G.H., An, S.H., Kang, K.I., "Comparison of construction cost estimating models based on regression analysis, neural networks, and case-based reasoning", Building and Environment, 39: 1235-1242, (2004).

[10] Sodikov, J., "Cost estimation of highway projects in developing countries: Artificial neural network approach", Journal of the Eastern Asia Society for Transportation Studies, 6: 1036-1047, (2005).

[11] Baykan, U.N., "Estimating resource requirements of construction projects with artificial neural networks approach", PhD Thesis, Gazi University, Ankara, 88-90, (2007).

[12] Öztürk, E., "Cost Estimation Of Trackworks Of Light Rail And Metro Projects", MS Thesis, METU, Ankara, 81-83, (2009).

[13] Bahadır, Y., "Using artifical neural networks (ANN) for estimation of the bid price of glass fibre reinforced cladding elements", MS Thesis, İstanbul Technical University, İstanbul, 55-58, (2013).

[14] Kasapl1, K., "Artificial neural networks usage for cost estimating on the water supply networks", MS Thesis, İstanbul Technical University, İstanbul, 75-80, (2014).

[15] Rui, Z.H., Metz, P.A., Reynolds, D.B., Chen, G., Zhou, X.Y., "Historical pipeline construction cost analysis", International Journal of Oil Gas and Coal Technology, 4(3): 244-263, (2011).

[16] Rui, Z.H., Metz, P.A., D.B., Chen, G., "An analysis of inaccuracy in pipeline construction cost estimation", International Journal of Oil Gas and Coal Technology, 5(1): 29-46, (2012).

[17] Clements, K.W., Si, J.W., "The investment project pipeline: cost escalation, lead time, success, failure and speed", Australian Journal of Management, 36(3): 317-348, (2011).

[18] Kaiser, M. J., Liu, M., "Cost factors and statistical evaluation of gas transmission pipeline construction and compressor-station cost in the USA, 2014-2019", International Journal of Oil Gas and Coal Technology, 26(4): 422-452, (2021).

[19] Kaiser, M. J., "A review of onshore and offshore pipeline construction and decommissioning cost in the USA - part 1: specifications, cost estimation and onshore construction", International Journal of Oil Gas and Coal Technology, 27(3): 247-285, (2021).

[20] Kaiser, M. J., "A review of onshore and offshore pipeline construction and decommissioning cost in the USA - part 2. Offshore and deepwater decommissioning cost algorithms", International Journal of Oil Gas and Coal Technology, 27(4): 363-398, (2021).

[21] Neter, J., Kunter, M., Nachtsheim, W., Wasserman, C., “Applied Linear Regression Models”, The Mc Graw-Hill Companies Inc., Chicago, (1996).

[22] Gündüz, M., Uğur, L.O., Öztürk, E., "Parametric cost estimation system for light rail transit and metro trackworks", Expert Systems with Applications, 38(3): 2873-2877, (2011). 
[23] Yılmaz, M., Kanıt, R., Erdal, M., Yıldız, S., Bakış, A., "Determination of the factors effecting the tender price by way of artificial neural networks and linear regression analyses in order to utilize maintenance and repair funds more effectively”, Journal of Polytechnic, 19(4): 461-470, (2016).

[24] Bostancioğlu, E., "Residential building envelope alternatives with equivalent cost", Gazi University Journal of Science, 24(2): 355-363, (2011).

[25] Sueri, M., "Estimating sewer line costs with artificial neural networks", MS Thesis, Gazi University, Ankara, 21-35, (2016). 